\title{
Review of Sommer, John Marcus. 2020. English and French Online Comments. A Text Linguistic Comparison of Popular Science Magazines. Berlin: Peter Lang. pp. 317. ISBN 978-3- 631-81977-7
}

\author{
Elena Alcalde Peñalver ${ }^{1}$ (1) https://orcid.org/0000-0002-1606-4792 \\ University of Alcalá \\ Facultad de Filosofía y Letras · Colegio San José de Caracciolos · c/ Trinidad, 3. $28801 \cdot$ Alcalá de Henares (Spain)
}

This book approaches a linguistic study of the popular sciences magazines National Geographic, Discover, Sciences et Avenir and GEO from a very original perspective, since the author aims to describe the changes within the genre profiles of the magazines and the differences and similarities between their journalistic cultures. More specifically, since nowadays we live in a world in which social networks are playing an increasingly important role in the journalistic field (Jiménez Cano, 2017), the author focuses on the communicative practices of the readers of these magazines in two languages (French and English) and three platforms (Facebook, Twitter and Magazine-Website) in their print and online versions. The research questions that are formulated to analyse the genre online comments of the study are answered in the first chapters considering both theoretical and empirical aspects. Regarding the corpus of texts, the author formulates more specific research questions which allow for a very thorough study in the second and more practical part of the book. Some of these research questions are the following: (1) What basic assumptions do disciplines such as cultural studies, linguistics and media studies make in order to research press texts and how can they help to investigate online comments? (2) What possibilities and constraints do concepts from text linguistics offer to describe genres and in what way will they have to be adapted for specific contexts? (3) What advantages and disadvantages does a contrastive analysis have and on what layers can cultural specific features of genres be found? All these research questions are answered in the 14 different chapters in which the book is structured, as it will be explained below.

The first four chapters (chapter 2,3,4 and 5) of the book provide a theoretical basis in which previous research and methods of analysing genres are presented. In this sense, the second chapter is very useful for the reader to understand basic concepts in the field of text linguistics that are going to be related to the analysis of readers' contributions to popular science magazines, such as what is considered a text and how to deal with it for communicative purposes. The author bases these explanations on very important studies from the existing literature and considers core features in the case of this research, such as multimodality. The third chapter is devoted to the concept of genre, first of all, as analytical categories and then considering its multiple layers (bearing in mind the different features that many authors have given to it as, for example, function, situation, topic, structure and form). Other important aspects that are explained in this chapter and that provide an overview of other uses of the study of genres are related to contrastive textology, genre change, intertextuality and their 
relation to culture. In chapter 4, the author conducts a very detailed study of previous literature related to the key parts for reader interaction that will be later analysed in the practical part of the book for the abovementioned four popular science magazines: letters to the editor, readers' comments, Facebook comments, Tweets, and Disqus \& Livefyre. For those who may not be familiar with this last concept, the author explains that it is an external form of communication which is used on popular websites and works in a way as a social networking site (p. 56). In chapter 5, on the topic of conversation analysis, the author further discusses the implications that this has for research in the field of linguistics and previous literature related to it. He then proceeds with a comparison of selection of some of the patterns of conversation analysis in which he provides the reader with very interesting examples. At the end of the chapter, the author explains the methodology that will be subsequently applied in the second part of the book. He applies a qualitative and quantitative methodology. For the qualitative analysis, he uses examples of conversations and considers for his study the participant structure, reactions, topics and strategies used by the participants. Some of the indicators for this are, for example, positive and negative politeness (Brown \& Levinson, 1992). For conflictual conversations, some of the indicators used are positive and negative impoliteness and aggression, criticism, blocking or challenges (Bousfield, 2008, among others). All these indicators provide evidence of a well-established methodology that can indeed be replicated for other related studies.

In Chapter six, the author explains the features of the corpus of the study. The author applies a multifactorial parallel text analysis but adapts the criteria for the choice of texts so that it also considers the online media of this study. Therefore, the texts, as stated before, had to be in two languages (English and Spanish); their origin had to be from more than two countries or from a country but written in different languages, and from the different magazines or platforms that were enumerated above. Moreover, the texts had to be from different media cultures (print and online) and from different epochal cultures (diachronic and synchronic).

In Chapter seven, the author provides an overview of the diachronic development of the genre letters to the editors in the print magazine. This is done with an illustrative example for each magazine in the years 1995, 2005, and 2014/2015, with the aim of studying "stable as well as unstable features of the genre" (p. 77). This is useful at this stage of the book to make a comparison among the different magazines and obtain results in this regard. In this same line, in chapter seven the author analyses the diachronic development but in this case of online comments. The research study moves on to focus on the diachronic development of online comments in chapter 8 based on the launch of the websites of the magazines during this period of time. The author illustrates the analysis with numerous different examples extracted from the comments sections of these websites, which is of great interest to compare and contrast results between them. In chapter 9, the author analyses the behaviour of the multiple comments, which are "readers who have published comments in at least two threads" (p. 127). The following types of multiple commenters are identified for this purpose: commenting multiple threads, comments to multiple articles, comments to multiple platforms and readers commenting over a long period of time. As in previous chapters, the author provides the reader with different real examples extracted from the magazines. The focus of chapter 10 lies on the layout, from a perspective of analysing, organising and ordering functions. The author describes the genre profile of the websites of the magazines with examples showing their structure and the logos, and he concludes that they show that "there are both national-cultural, as well as magazine-specific differences. What seems to be an arbitrary choice (e.g., the choice of colours on the website) is more likely to be a conscious decision and reflects in some cases the traditions and conventions of a magazine" (p. 148). This choice is also very interesting considering the inherent multimodality features of the research study conducted in this book. In chapter 11, the author deals with the communicative situation of the genre in which 
the participation framework and the time over which the threads develop are included. Chapter 12 is devoted to topic management in which the focus of analysis is if the conversations that appear on the platforms are actually about the articles published by the magazines. As done in previous chapters, the author illustrates the results of the analysis with different real examples extracted from the magazines.

The qualitative analysis starts in chapter 13 and it is divided in seven sections: (1) conflict conversations, (2) complete support conversations, (3) sharing with friends, (4) the use of links, (5) the use of emoticons, (6) hashtags and (7) quote article. The quantitative analysis is developed in chapter 14 and has four different sections: language comparison, platform comparison, comparison of overall magazine websites and discussion of results. Based on all the chapters we can agree with what is stated by the author in the conclusions: "The results of the present study show that a multifactorial parallel text analysis is a method that makes it possible to examine the complex web of norms of cultures that use certain genres" (p. 247).

Overall, the different chapters of this book make it a very interesting starting point for researchers seeking for a theoretical basis in the field of linguistics, as well as a practical approach, on how to apply this theory in a very timely and necessary manner to analyse textual information. As stated by the author (p. 59), "communication forms of the online genres seem to bring about a higher potential for conversations than the offline communication forms" and this is something that has not be sufficiently researched up to date. Thus, the results of the book contribute indeed to the existing literature and make it an asset for scholars and students with an interest to continue learning and exploring this field for different and useful communication purposes. The author also explains the different characteristics of each of the magazines with specific data about their readers and online visitors.

\section{Declaration of conflicting interests}

The author(s) declared no potential conflicts of interest with respect to the research, authorship, and/or publication of this article.

\section{Funding}

The author(s) received no financial support for the research, authorship, and/or publication of this article.

\section{About the author}

Elena Alcalde Peñalver is a researcher and professor at the University of Alcalá and holds a PhD on Financial Translation from the University of Granada (Spain). She also works as a freelance translator and interpreter and has teaching and research experience at national and international level in the fields of foreign languages and translation. 


\section{References}

Bousfield, D. (2008). Impoliteness in Interaction. Amsterdam: Benjamins.

Brown, P. \& Levinson, S. C. (1992). Politeness. Some Universals in Language Usage. Cambridge: Cambridge University Press.

Jiménez Cano, R. (2017). Twitter® aumenta el límite a 280 caracteres para todos los usuarios. El País. <https://elpais.com/tecnologia/2017/11/07/actualidad/1510037858 189762.html\#: :text=En\%2010\%20sucesivo\%2C $\% 20 \mathrm{el} \% 201$ \%C3\%ADmite,pocas $\% 20$ semanas $\% 2010 \% 20$ tendr $\%$ C $3 \%$ A $1 \mathrm{n} \% 20$ todos $>~[10 / 02 / 2021]$. 